\title{
SPATIAL ECONOMICS MODEL PREDICTING TRANSPORT VOLUME
}

Bo LU

Institute of Electronic Commerce and Modern Logistics, Dalian University

\begin{abstract}
It is extremely important to predict the logistics requirements in a scientific and rational way. However, in recent years, the improvement effect on the prediction method is not very significant and the traditional statistical prediction method has the defects of low precision and poor interpretation of the prediction model, which cannot only guarantee the generalization ability of the prediction model theoretically, but also cannot explain the models effectively. Therefore, in combination with the theories of the spatial economics, industrial economics, and neo-classical economics, taking city of Zhuanghe as the research object, the study identifies the leading industry that can produce a large number of cargoes, and further predicts the static logistics generation of the Zhuanghe and hinterlands. By integrating various factors that can affect the regional logistics requirements, this study established a logistics requirements potential model from the aspect of spatial economic principles, and expanded the way of logistics requirements prediction from the single statistical principles to an new area of special and regional economics.
\end{abstract}

Keywords: Spatial economics, Logistics requirements potential model, Regional logistics prediction

\section{INTRODUCTION}

The logistics requirements prediction is to predict the changes of the logistics requirements and its development trend by virtue of judgment, technical method and model according to the past and current requirements of the logistics markets and the relationship among the factors that affect the changes in the logistics market requirements.

The regional logistics requirements prediction was firstly proposed in the 1990s [2]. After nearly 20 years of development, it has made great progress. By sorting out comprehensive overview about existing method, most researchers deal with them as a regression problem. According to the development process and the level of intelligence, it can be roughly divided into three stages:
The prediction method based on statistics in the first stage. Main methods include regression analysis [4], elasticity coefficient method [1], freight intensity method, clustering method, gray theory model [5], Markov chain [3], inputoutput model [7], space-time multi-term probability model and decision support system, etc [9]. The major features of this type of methods can process the sequencing and linear data, and explain the construct models effectively. With the deepening of the study, many defects of the research methods are exposed: firstly, there are very few regional logistics requirements data samples, which are difficult to be collected and is harmful for the validation of the prediction method. Secondly, it is not ideal for processing the regional logistics requirements data with high dimension, non-linear relationship, non-normal distribution and chronological 
order [32]. Thirdly, lack of flexibility, which cannot guarantee the learning and generalization ability and will process all data in the same way whether it is required or not.

The prediction method based on artificial intelligence in the second stage. Later on, to enhance the prediction accuracy, the researcher [10] adopted the artificial intelligence method, such as the artificial neural network (ANN) and its improvement model. By introducing the artificial intelligence factors into the traditional method, such as the learning and generalization ability of neural networks, expert system inference rules, etc, then the regional logistics requirements prediction accuracy can be improved. However, there are still the following problems: firstly, it cannot guarantee the generalization capability of the prediction model, which makes it no stable prediction effect for the new logistics requirements data sets for the prediction model after training. Secondly, when the number of study samples is limited, the learning process error is easy to converge to local minima, hence the learning accuracy is difficult to guarantee; when there is more sample variables, it will come to the "disaster of dimensionality" [32]. Thirdly, it mainly relies on the empirical risk minimization principle, and its main defects are: to select the decision-making function with the empirical risk instead of the expected risk is not subject to strict testifying and full demonstration, which is only a reasonable way; it is easy to lead to "overlearning". It is an inevitable result by blind pursuit of small errors, which causes decrease in the generalization ability [21].

The prediction methods based on statistical learning theory is the third stage. To further enhance the accuracy and stability of the prediction models, in recent years, the researchers started to explore the prediction method based on the principle of structural risk minimization [8]. Such methods are represented by the support vector machine (SVM). Although certain achievements have been made, some urgent problems still exist in the regional logistics requirements prediction [11], mainly as follows: first, when the quantity of learning samples is limited, the learning process error is easy to converge to a local minimal point, and the learning accuracy is difficult to guarantee; when there are many learning sample variables, they fall into the "dimension disaster" [23]. Second, mainly rely on the empirical risk minimization principle. Therefore, the generalization capability of the prediction model cannot be guaranteed from theory, which makes the predictive models after training to have no stable prediction effect for the new logistics requirements data set. Third, since the concept of regional logistics has been introduced to China for not a long time, many logistics standards are not unified, and also lack of direct statistical data. The historical data for researching prediction have to be substituted by the related cargo quantity, which affect the empirical study of the prediction methods [12]. Especially in china, most of the literatures $[6,13]$ are only an overview of the method, and almost no actual regional logistics data are used for predictive analysis [15], which makes many studies lack of practical significance. Fourth, the selection method of indicators of regional logistics mainly which support the prediction $[14,16]$, relies on the experiences of the industry researchers and practitioners, the principal component analysis, factor analysis and other traditional methods, hence they are lack of new research method. Fifth, among these methods, although the artificial intelligence methods and support vector machine method have certain advantage in the prediction of accuracy, it still cannot explain the models effectively [31].

As seen from the above analysis, the researches in the present stage are mainly restricted by the non-unified logistics standard. Under the condition of lack of direct statistical data, to continue the logistics requirements prediction from the perspective of regression statistics cannot guarantee the prediction accuracy, nor explain the models effectively [22].

Regional logistics requirements is a derived requirements determined by the level of regional economic development, therefore, the indicators that affect the regional logistics requirements prediction such as economic factors (mainly including: the overall level and scale of the regional economy, industrial structure and product structure of the regional economy and the spatial layout of the regional economy, etc), logistics industry factors (mainly including: logistics facilities and services, changes in logistics costs, etc.), environmental factors (mainly including: technological progress, economic policies and institution, etc), as well as other factors (mainly including: regional geographic location, emergency factors, etc.), will directly or indirectly affect the growth or reduction of the regional logistics requirements [17].

Therefore, by integrating various factors that affect the regional logistics requirements, this study explores the logical relationship between the regional logistics requirements and many other relevant factors based on the spatial economics and new economic geography, etc, and from the perspective of market potential in the space economic principles [27-29], then this study established the logistics requirements gravity model and expanded the logistics requirements prediction way from the single statistical principles to the new area of space economics and regional economics, to enrich the research method of the regional logistics requirements.

In recent years, among the relevant study in spatial economics, the theoretical breakthrough made by the economists [24] brought a new wave of the industrial clustering study [26]. But regrettably, there is still very less experiences and empirical support in the logistics industry clustering and logistics requirements prediction [19]; therefore, this study expects to make some efforts in this area.

The paper is structured as follows: after the introductory section of Chapter 1, there will be followed by the description of the logistics requirements potential model. In so doing, the research procedure is included in Chapter 2. Moreover, the research scope and logistics requirements prediction in Chapter 3. Finally, conclusions are drawn in Chapter 4. 


\section{RESEARCH METHOD}

\section{LOGISTICS REQUIREMENT POTENTIAL MODEL}

The concept of market potential was firstly proposed by Harris [17], which can be described that, as a place of production, the decision of region depend on the easy accessibility of market in this area. The measurement on the accessibility is the market potential index, which can be expressed by the formula: $M_{j}=\sum_{k} Y_{k} g\left(D_{j k}\right)$, where, $M_{j}$ is the market potential of place $j$; $Y_{k}$ is the incomes of the all regions; $\mathrm{Y}_{\mathrm{k}} \mathrm{g}\left(\mathrm{D}_{\mathrm{jk}}\right)$ is the decay function of distance; $\mathrm{D}_{\mathrm{jk}}$ is the distance between place $j$ and place $k$. Harris' market potential model, howevr, has no micro-structure, which only showed that the market potential is proportional to market purchasing power of various places (i.e. the market scale), and inversely proportional to the distance from this place to the market.

But the theoretical innovation on this issue as a special field was originated from the early 1990s when Krugman and Fujita, et al built the New Economic Geography [18, 20]. The economists represented by Krugman studied the business location choice behavior to maximize the profits, and proposed the market potential model based on the monopolistic competition, increasing returns to scale and iceberg transport cost, general equilibrium framework including the enterprise subject decision behaviors. [25] claimed that two forces determine whether the economic behavior and economic factors are convergent or diffusive in spaces in the model: centripetal force and centrifugal force. The centripetal force makes the economic activities and economic elements to reflect the industrial agglomeration in the spatial distribution in the industry level, which is why the new economic geography and spatial economics attaches great importance to industrial agglomeration [26].

However, [19] who proposed the potential model just from the perspective of economic scale and regional economic agglomeration. On the basis of the market potential model, this paper has introduced the related logistics factors, including a series of related indicators such as overall level and scale of the regional economy, regional cargo output, and economic distance, to construct the logistics requirements potential model:

$$
P_{i}=k_{i j} \frac{M_{i}^{a_{i}} M_{j}^{a_{j}}}{E D_{i j}^{b}}
$$

Where, $P_{i}$ is the potential value between city $i$ and $j, k_{i j}$ is the weight, which reflects the contribution rate of the city $\mathrm{i}$ on the centripetal force; $\mathrm{M}_{\mathrm{i}}, \mathrm{M}_{\mathrm{j}}$ respectively represent the scale of two cities (such as gross national product, logistics volume, population, etc.), $a_{i}$, $a_{j}$ are the indices, which reflect the space liquidity difference, $\mathrm{ED}_{\mathrm{ij}}$ is the economic distance between the two geographic locations, and $\mathrm{b}$ is the friction coefficient of distance.

Since the two cities have different contributions to the centripetal force, it is required to calculate its contribution on the centripetal force when calculating the potential of city $i$ according to the following formula:

$$
\begin{aligned}
& k_{i j}=\left[\frac{G D P_{i}}{G D P_{i}+G D P_{j}}\right] \times\left[\frac{Q_{\text {total }-i}}{Q_{\text {total }-i}+Q_{\text {total }-j}}\right] \times \\
& {\left[\frac{Q_{\text {industry-i }}}{Q_{\text {industry }-i}+Q_{\text {industry }-j}}\right]}
\end{aligned}
$$

Where, $\mathrm{GDP}_{\mathrm{i}}$ and GDP $\mathrm{G}_{\mathrm{j}}$ are respectively the GDP of cities $\mathrm{i}$ and j; $\mathrm{Q}_{(\text {total-i) }}$ and $\mathrm{Q}_{\text {(total-j) }}$ are respectively the production of goods of cities i and $j ; \mathrm{Q}_{\text {(industry-i) }}$ and $\mathrm{Q}_{\text {(industry-j) }}$ are respectively the production of goods of the dominant and leading industry in cities $i$ and $j$.

According to assumptions ( $\mathrm{Li}, 2008$ ), in this paper, the $\sqrt{ }\left(Q_{i} \times Q_{j}\right)$ (the product of cargo quantity) represents the city size; the combined proportion of highway, railway and waterway is used to calculate the economic distance:

$$
\begin{aligned}
& E D_{i j}=\alpha \times C_{\text {higuway-ij }} \times D_{\text {highway-ij }}+ \\
& \beta \times C_{\text {railway- } i j} \times D_{\text {railway-ij }}+\gamma \times C_{\text {waterway- } i j} \times \\
& D_{\text {waterway- } i j}
\end{aligned}
$$

Where, $\mathrm{C}$ is the transportation cost, $\mathrm{D}$ is the spatial distance between two cities, $\alpha, \beta, \gamma$ are transport weights calculated by three transport modes. According to (Luo, 2010), this paper has set the distance friction coefficient to 2 .

Therefore, the formula of the logistics requirements potential model can be changed as:

$$
P_{i}=k_{i j} \frac{\sqrt{Q_{i} \times Q_{j}}}{E D_{i j}^{2}}
$$

\section{RESEARCH PROCEDURE}

By constructing the model of the logistics requirements potential, this paper has predicted the logistics requirements of Zhuanghe, which not only avoids the double counting of the cargo quantity, but also calculate the logistics requirements potential value of Zhuanghe, and sort the logistics requirements potential values in various cities within the system.

Let Zhuanghe as the researche center, this study, firstly, need identify the cities which have high relevance with logistics of Zhuanghe to jointly constitute a logistics system. Then, based on the leading industry of Zhuanghe, this study could predict the cargo output of each city in these industries by data fitting.

When predicting the logistics requirements based on the logistics requirements potential model, this study, firstly, need calculate five parameters which are the GDP weight, weight of the cargo quantity, weight of the industry cargo quantity, weight of the city logistics scale, and economic distance; then the study should respectively calculate the logistics requirements of the leading industries in each city, that is, by applied with the logistics requirements potential model, this study, firstly, calculates the logistics potential value of the leading industry in each city, and by normalization processing, the weight of the potential value 
can been obtained, and then multiply the total production of cargo of this industry within the system, to obtain the logistics requirements of each industry within the system in each city. The formula is:

Logistics Requirements of City Industry $_{j}=$ Potential Value Weight $\times$

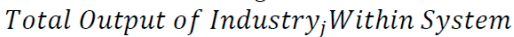

\section{RESULT ANALYSIS}

\section{RESEARCH SCOPE}

The study is centring on city of Zhuanghe, scope of I, II, III area surrounding, I area is as per radius of $100 \mathrm{kms}$, II area is as per radius of $100 \sim 300 \mathrm{kms}$, III area is as per radius of $300 \sim 500 \mathrm{kms}$, and IV area are the cities along the "east-railway".

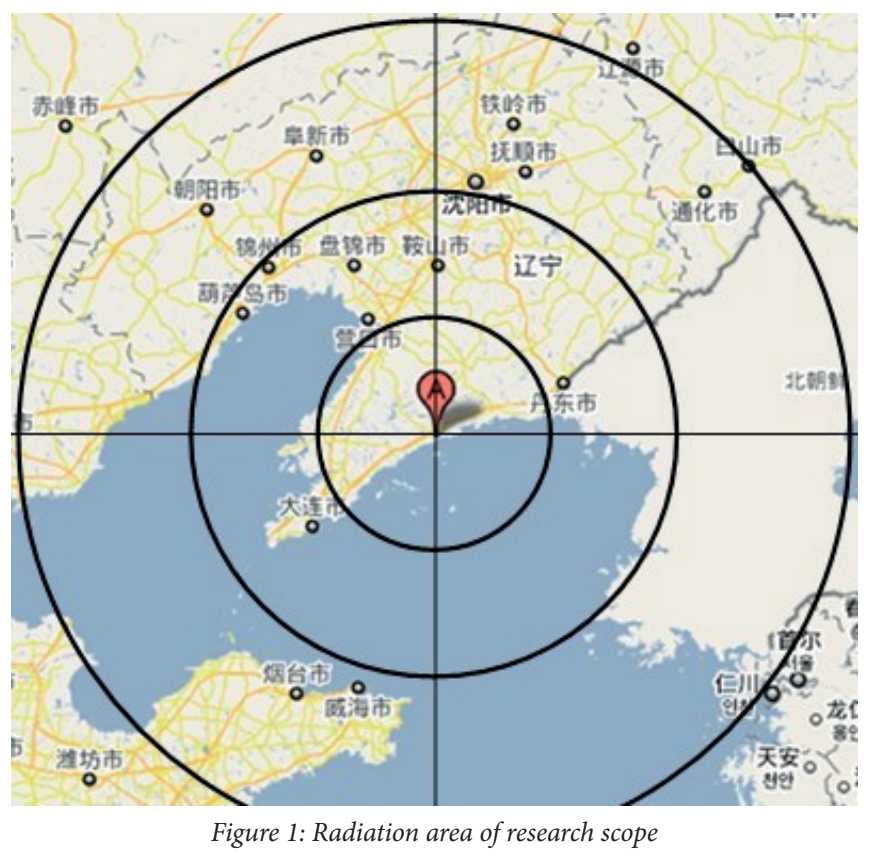

Definition of I, II, III surrounding areas is as following: central city: Zhaunghe; I area: Wafangdian and Pulandian; II area: Yingkou, Dandong, Dalian, Anshan, Panjin, Jinzhou and Huludao; III area: Shenyang, Fushun, Tieling, Fuxin, Chaoyang, Yantai, Weihai, Tonghua and Baishan; IV area: Hegang, Jiamusi, Shuangyashan, Yanji, Jixi, Mudanjiang and Qitaihe.

\section{PREDICTION FOR STATIC CARGO QUANTITY}

Zhuanghe is located between Dalian and Dandong, the centre of the Northeast Asia economic circle. With the advantage of location, resources and industry, it is one of the windows for the opening-up in Liaodong Peninsula. As the construction of eastern border railway in Northeast, HD-highway, ZG-highway, ZX-railway, Binhai National Road and the national first level ports in Zhuanghe, Zhuanghe will become an important sea port city in Northeast eastern region, and also an important node for commodity exchange in the Northeast to Japan, South Korea and North Korea.

In addition to the geographic advantages, the rapid economic development of Zhuanghe has direct correlation with its industrial structure. The major industry in Zhuanghe is the second industry with relatively complete category, including its three superior industries: agro-food processing industry, machinery and equipment manufacturing and furniture manufacturing, which account for a large proportion of the industrial added value. In addition, the rapid development of the above-scale general equipment manufacturing industry, transportation equipment manufacturing industry \& communications equipment, computer \& other electronic equipment manufacturing industry will bring a large quantity of logistics requirements.

Economic development speed of Zhuanghe has direct correlations with its industrial structure. By combining with the status of economic development, this study has mainly analyzed the following 16 industries which are Farming, Animal husbandry, Aquatic products, Food processing, Food manufacturing, Textile and apparel, Furniture manufacturing, Plastic products, Special equipment manufacturing, Fabricated metal products, General equipment manufacturing, Transportation equipment manufacturing, Electrical machinery manufacturing, Communications and electronic equipment, and Flow of commerce.

Based on data collection of site survey, statistical yearbooks and bulletins, this study, firstly, has calculated the static cargo qiantity of 16 industries of Zhanghe and surrounding four areas by means of data fitting, $\mathrm{Q}_{\mathrm{n}}=\mathrm{Q}_{0} \times(1+\mathrm{x})^{\mathrm{n}-1}$. It is shown in table 1.

\section{PREDICTION FOR DYNAMIC LOGISTICS REQUIREMENTS}

Within the system (four area) composed by 26 cities centering Zhuanghe, Zhuanghe is located in the narrow space. Therefore, it is required to accurately calculate the logistics in the environment, and it is also critical to carry out accurate logistics industry positioning under the competitive environment.

When predicting the logistics requirements based on the logistics requirements potential model, this study firstly should calculate the five parameters which include: GDP weight, weight of cargo quantity, weight of industry cargo quantity, weight of city logistics scale, and economic distance.

The predicting values of GDP in year 2015, and economic distance between Zhuanghe and other cities have been summarized in table 2 and table 3 , respectively.

Within the 26 cities, each city has its different key industry type, therefore, the production and consumption have different features. Juding the leading industry based on Zhuanghe, this study has predicted the logistics requirements of these industries in each city. Firstly this study has calculated the potential value of logistics requirements of the leading industry in each city. 


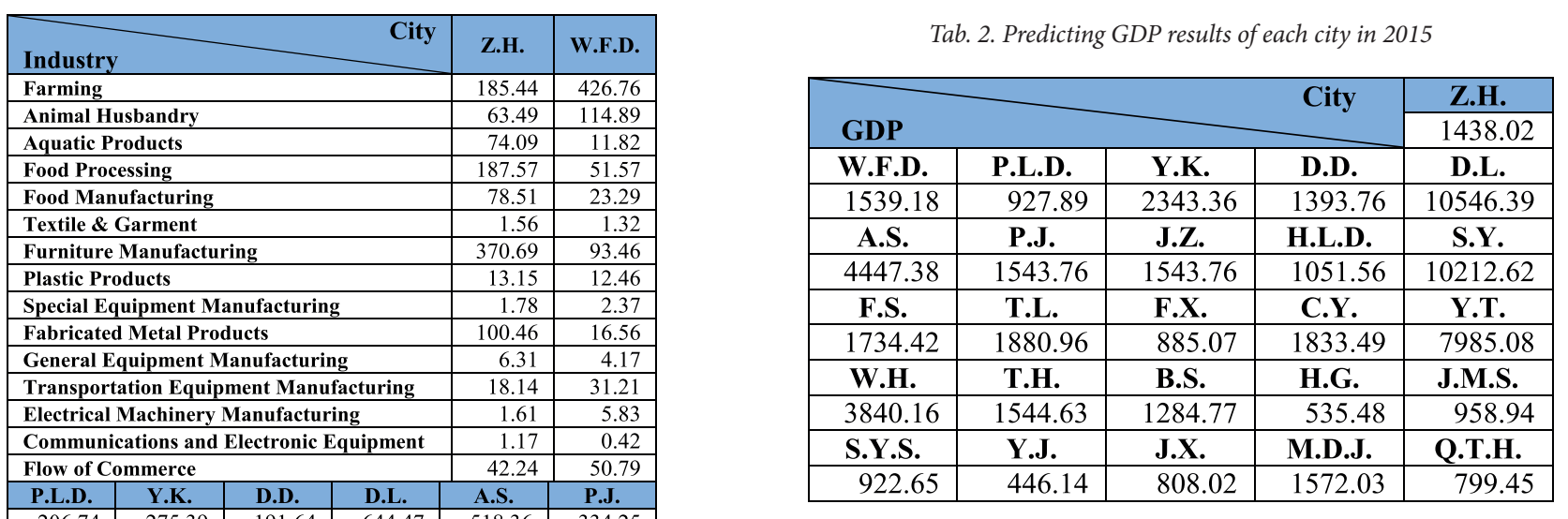

Tab. 3. Economic distance from Zhuanghe to other Cities

\begin{tabular}{|c|c|c|c|c|}
\hline \multicolumn{5}{|c|}{ From Zhuanghe to other Cities } \\
Economic distance \\
\hline W.F.D. & P.L.D. & Y.K. & D.D. & D.L. \\
\hline 2275.29 & 2481.53 & 3535.49 & 1005.71 & 4830.57 \\
\hline A.S. & P.J. & J.Z. & H.L.D. & S.Y. \\
\hline 8927.40 & 8937.06 & 41031.00 & 49188.79 & 17509.48 \\
\hline F.S. & T.L. & F.X. & C.Y. & Y.T. \\
\hline 20037.82 & 22769.72 & 22749.33 & 52573.22 & 12100.51 \\
\hline W.H. & T.H. & B.S. & H.G. & J.M.S. \\
\hline 12544.52 & 2162.25 & 2652.25 & 6642.25 & 10261.69 \\
\hline S.Y.S. & Y.J. & J.X. & M.D.J. & Q.T.H. \\
\hline 12723.84 & 13947.61 & 17715.61 & 16205.29 & 17768.89 \\
\hline
\end{tabular}

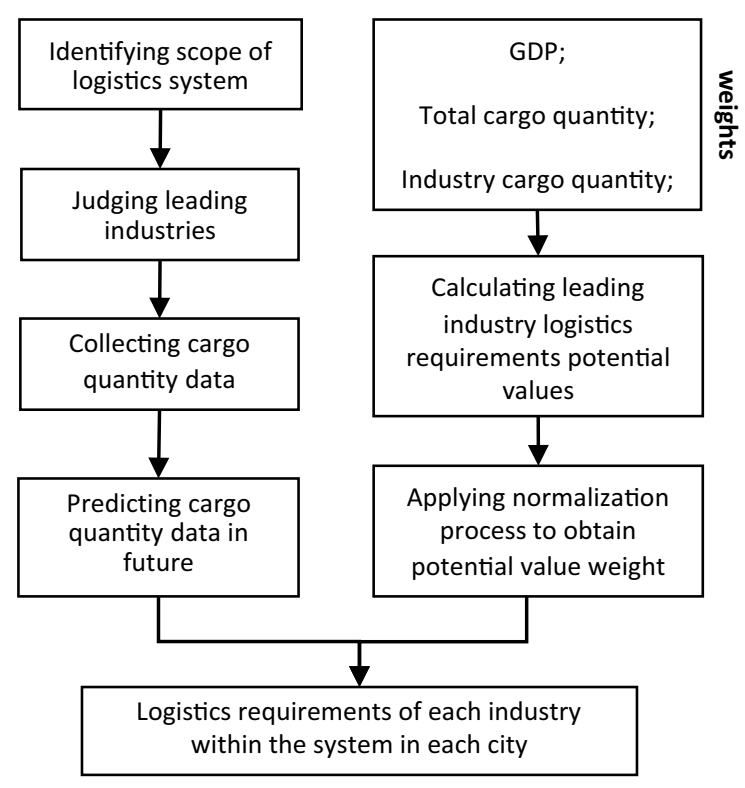

Fig. 2. Research procedure

By applying the normalization process, the weight of the potential value could been obtained. Then, the logistics requirements of each industry within the system in each city, can been calculated by the weight of the potential value multiply by total cargo quantity of this industry within the system. The predicting logistics requirements of Zhuanghe 
in 2015 , have been summarized in table 4 , and the following observations can be made.

Tab. 4. Predicting logistics requirements of Zhuanghe

\begin{tabular}{|l|r|r|r|c|}
\hline \multicolumn{1}{|c|}{ Industry } & \multicolumn{1}{c|}{ C.Q. } & \multicolumn{1}{c|}{ Log.R. } & \multicolumn{1}{c|}{ Var. } & Rank \\
\hline Farming & 185.44 & 245.99 & $\mathbf{6 0 . 5 5}$ & $\mathbf{1 3}$ \\
\hline Animal H. & 63.49 & 95.15 & $\mathbf{3 1 . 6 6}$ & $\mathbf{1 2}$ \\
\hline Aquatic P. & 74.09 & 90.99 & $\mathbf{1 6 . 9}$ & $\mathbf{4}$ \\
\hline Food P. & 187.57 & 259.06 & $\mathbf{7 1 . 4 9}$ & $\mathbf{8}$ \\
\hline Food M. & 78.51 & 87.62 & $\mathbf{9 . 1 1}$ & $\mathbf{6}$ \\
\hline T. \& A. & 1.56 & 3.30 & $\mathbf{1 . 7 4}$ & $\mathbf{1 4}$ \\
\hline F. M. & 370.69 & 429.23 & $\mathbf{5 8 . 5 4}$ & $\mathbf{3}$ \\
\hline Plastic P. & 13.15 & 36.58 & $\mathbf{2 3 . 4 3}$ & $\mathbf{1 0}$ \\
\hline Special E. M. & 1.78 & 9.48 & $\mathbf{7 . 7}$ & $\mathbf{1 6}$ \\
\hline F. M. P. & 100.46 & 105.05 & $\mathbf{4 . 5 9}$ & $\mathbf{3}$ \\
\hline General E. M. & 6.31 & 22.34 & $\mathbf{1 6 . 0 3}$ & $\mathbf{1 5}$ \\
\hline T. E.M. & 18.14 & 25.07 & $\mathbf{6 . 9 3}$ & $\mathbf{1 5}$ \\
\hline E. M. M. & 1.61 & 11.67 & $\mathbf{1 0 . 0 6}$ & $\mathbf{2 5}$ \\
\hline C. \& E.E. & 1.17 & 13.47 & $\mathbf{1 2 . 3}$ & $\mathbf{1 6}$ \\
\hline F. C. & 42.24 & 51.76 & $\mathbf{9 . 5 2}$ & $\mathbf{1 5}$ \\
\hline \multicolumn{6}{|c|}{ Sum } & 1146.21 & 1486.76 & $\mathbf{3 4 0 . 5 5}$ & - \\
\hline C.Q.: Cargo quantity. & \\
\hline Log. R.: Logistics requirements \\
\hline Var.: Variation. \\
\hline
\end{tabular}

The column and row totals represent, respectively, the static cargo quantity, dynamic logistics requirements of Zhaunghe and the variation in 2015 year.

It is clear from table 4 that, the static cargo quantity yields lower than the dynamic logistics requirements in each industry. This result indicates that the logistics potential value is greater than average level, threrfore the variation is positive. However, in sort order of industies competitive power, most industries of Zhuanghe are disadvantageous, except the industry of Aquatic Products, Food Manufacturing, Furniture Manufacturing and Fabricated Metal Products, thus indicating that the four leading industries has played the role of logistics engine, and Zhuanghe municipal government would need give policy support to them.

\section{CONCLUSIONS}

As a gathering node of logistics companies and logistics devices, logistics parks has become an important theme pushed forward by provinces and zones. According to incomplete statistics, there are several hundreds of logistics park, logistics base or logistics centre being planned and constructed at present. With its status confirmed on a national level, especially its important role in the service industry, logistics industry is one of the key items planned and developed by all levels of governments and is served as a new economic growth point in many zones.

Northeastern old industrial base reconstruction brings historical development chance and policy advantage for development of logistics industry in Zhuanghe. The state has intensified support for infrastructure construction in liaoning Regions so that such tangible infrastructures as communication, road traffic and urban infrastructures have an obvious improvement. Especially the improvement of transportation conditions is a powerful precondition for the development of the logistics industry. Zhuanghe has accelerated construction of logistics infrastructures continuously in recent years, such as logistics parks.

However, it is not all logistics parks have well played the role of logistics engine expected by us. In fact, there are no enterprises settling in most logistics parks and the vacancy rate is as high as $60 \%$, resulting in huge wasting of resources. Therefore, construction of logistics parks should follow a uniform planning and should not be repeated. Because of that, a scientific prediction is a basic work for proper planning of logistics parks, which is also important to analyze the proper construction scale of logistics parks.

Furthermore, from the prospective of macro economic development of industries, the various regional logistics development strategies and regional logistics plan cannot been formulated without a quantitative analysis of regional logistics requirements. The first question occurred in logistics planning is the prediction for the scale of macro logistics market. Prediction of regional logistics requirements could provide a basis in theory for national and regional economic administrations. In addition, according to prediction of regional logistics requirements, the government could evaluate the contribution of the logistics industry to local economic development which is useful in helping the government to formulate for the logistics industry and guide optimum configuration of resources in the logistics market.

From a micro perspective, logistics enterprises should properly configure limited resources according to the prediction of logistics requirements in order to minimize investment risks and maximize benefits. Thus, a scientific prediction of regional logistics requirements is a very important task.

\section{ACKNOWLEDGMENTS}

This work was supported by the National Natural Science Foundation of China (71573028); 2014 Liaoning BaiQianWan Talents Program (2014Q013); Liaoning Social Science Planning Fund Plan (L14CJY041); Liaoning Provincial Education Department (WJQ2015004); Dalian science and technology project (2015D21ZC001;2014D11ZC117); Program for Liaoning Excellent Talents in University (WJQ2015004); Dalian Jinzhou Science and technology project (RXYJ-RXSK-2015-002); Liaoning educational scientific research management think tank project (ZK2015090).

\section{REFERENCES}

1. Adolf K.Y. Ng, Flavio Padilha, Athanasios A. Pallis, (2013). Institutions, bureaucratic and logistical roles of dry ports: the Brazilian experiences [J] Journal of Transport Geography, Vol. 27, No. 2, Pages 46-55, 2013.

2. Andrawis, R. R., Atiya, A. F., El-Shishiny, H., (2011). 
Combination of long term and short term forecasts, with application to tourism demand forecasting [J] International Journal of Forecasting, Vol. 27, Pages 870-886, 2011.

3. Anna, B., Maurizio, C., Claudio, F., Alessio T., (2014). Ports and regional development: A spatial analysis on a panel of European regions [J] Transportation Research Part A: Policy and Practice, Vol. 65, Pages 44-55, 2014.

4. Babai, M.Z., Ali, M., Nikolopoulos, K., (2012). Impact of temporal aggregation on stock control performance of intermittent demand estimators: empirical analysis. [J] International Journal of Management Science, Vol. 40, Pages 713-721, 2012.

5. Bacchetti, A., Saccani, N., (2012). Spare parts classification and demand forecasting for stock control: investigating the gap between research and practice [J] International Journal of Management Science, Vol. 40, Pages 722-737, 2012.

6. Bandyopadhyay, S., Bhattacharya, R. (2013). A generalized measure of bullwhip effect in supply chain with ARMA demand process under various replenishment policies [J] International Journal of Advance Manufacturing Technology, Vol. 68, Pages 963-979, 2013.

7. Briant, A., Combes, P.-P., Lafourcade, M., (2010). Dots to boxes: do the size and shape of spatial units jeopardize economic geography estimations? [J] Urban Economics, Vol. 67, No. 3, Page 287-302, 2010.

8. Cang, S., Yu, H., (2014). A combination selection algorithm on forecasting [J] European Journal of Operational Research, Vol. 234, Pages 127-139, 2014.

9. Chris Jacobs-Crisioni, Piet Rietveld, Eric Koomen, (2014). The impact of spatial aggregation on urban development analyses [J] Applied Geography, Vol. 47, Pages 46-56, 2014.

10. Colin Wren, (2012). Geographic concentration and the temporal scope of agglomeration economies: an index decomposition [J] Regional Science and Urban Economics, Vol. 42, Issue 4, Pages 681-690, 2012.

11. Crone, S. F., Hibon, M., Nikolopoulos, K., (2011). Advances in forecasting with neural networks? empirical evidence from the NN3 competition on time series prediction [J] International Journal of Forecasting, Vol. 27, Pages 635660, 2011.

12. David A. Hensher, Truong P. Truong, Corinne Mulley, Richard Ellison, (2012). Assessing the wider economy impacts of transport infrastructure investment with an illustrative application to the north-west rail link project in Sydney, Australia [J] Journal of Transport Geography, Vol. 24, No. 9, Pages 292-305, 2012.

13. Dongya Li, Yi Lu, Mingqin Wu, (2012). Industrial agglomeration and firm size: evidence from China [J] Regional Science and Urban Economics, Vol. 42, Issues 1-2, Pages 135-143, 2012.

14. Dixit, A.K., Stigiitz, J.E., (1977). Monopolistic competition and optimum product diversity [J] American Economic Review, Vol. 67, Pages 298-302, 1977.

15. Echeverri-Carroll, E., Ayala, S.G., (2010). Gender wage differentials and the spatial concentration of hightechnology industries [J] Progress in Spatial Analysis, Pages 287-309, 2010.

16. Eric Nitzsche, Stefan Tscharaktschiew, (2013). Efficiency of speed limits in cities: a spatial computable general equilibrium assessment [J] Transportation Research Part A: Policy and Practice, Vol. 56, No. 10, Pages 23-48, 2013.

17. Feo-Valero, M., García-Menéndez, L., Sáez-Carramolino, L., Furió-Pruñonosa, S., (2011). The importance of the inland leg of containerized maritime shipments: an analysis of modal choice determinants in Spain [J] Transportation Research Part E, Vol. 47, Pages 446-460, 2011.

18. Frank P.van den Heuvel,Peter W.de Langen, Karel H.van Donselaar, Jan C.Fransoo, (2013). Regional logistics land allocation policies: stimulating spatial concentration of logistics firms [J] Transport Policy, Vol. 30, Pages 275-282, 2013.

19. Frank, P., Liliana, R., Karel, H., Jong, A., Yossi, S., Peter, W., Jan, C., (2014). Relationship between freight accessibility and logistics employment in US counties [J] Transportation Research Part A: Policy and Practice, Vol. 59, Pages 91-105, 2014.

20. Frémont, A., Franc, P., (2010). Hinterland transportation in Europe: combined transport versus road transport [J] Journal of Transport Geography, Vol. 18, No. 4, Pages 548-556, 2010.

21. Fujita M, Krugman P., (2004). The new economic geography: Past, present and the future [J] Regional Science, Vol. 83, Pages 139-164, 2004.

22. Garcia-Alonso, L., Sanchez-Soriano, J., (2010). Analysis of the evolution of the inland traffic distribution and provincial hinterland share of the Spanish port system [J] Transport Reviews, Vol. 30, No. 3, Pages 275-297, 2010.

23. Gianmarco I.P. Ottaviano, (2012). Agglomeration, trade and selection [J] Regional Science and Urban Economics, Vol. 42, Issue 6, Pages 987-997, 2012.

24. Hyok-Joo Rhee, Sanggyun Yu, Georg Hirte, (2014). Zoning in cities with traffic congestion and agglomeration economies [J] Regional Science and Urban Economics, Vol. 44, No. 1, Pages 82-93, 2014. 
25. Ingrid Ott, Susanne Soretz, (2010). Productive public input, integration and agglomeration [J] Regional Science and Urban Economics, Vol. 40, Pages 538-549, 2010.

26. Lei Fan, William W. Wilson, Bruce Dahl, (2012). Congestion, port expansion and spatial competition for US container imports [J] Transportation Research Part E: Logistics and Transportation Review, Vol. 48, Issue 6, Pages 1121-1136, 2012.

27. Marufuzzaman, M., Eksioglu, S.D., Li, X.P., Wang, J., (2014). Analyzing the impact of intermodal-related risk to the design and management of biofuel supply chain [J] Transportation Research Part E: Logistics and Transportation Review, Vol. 69, Pages 122-145, 2014.

28. Tomasicchio, GR; D’Alessandro, F. Wave energy transmission through and over low crested breakwaters [J] Journal of Coastal Research. SI 65, Pages 398-403, 2013.

29. Zastempowski, M; Bochat, A. Mathematical modelling of elastic deflection of a tubular cross-section [J] Polish Maritime Research. Vol. 22(2), Pages 93-100, 2015.

30. Masahisa Fujita, Nobuaki Hamaguchi, (2001). Intermediate goods and the spatial structure of an economy [J] Regional Science and Urban Economics, Vol. 31, Issue 1, Pages 79-109, 2001.

31. Masahisa Fujita, Tomoya Mori, (1996). The role of ports in the making of major cities: self-agglomeration and hubeffect [J] Development Economics, Vol. 49, Pages 93-120, 1996.

32. Krugman, Paul, (1991). Increasing returns and economic geography [J] Political Economy, Vol. 99, Pages 483-499, 1991.

\section{CONTACT WITH AUTHOR}

\section{Bo LU}

Research center of electronic commerce

$\&$ modern logistics,

Xuefu road \#10,

Dalian economic technological development zone, 116022, China.

E-mail: lubo_documents@hotmail.com 